Int. J. Electrochem. Sci., 13 (2018) 8970 - 8982

International Journal of

ELECTROCHEMICAL

SCIENCE

www.electrochemsci.org

\title{
Effect of Extrusion Texture on Corrosion Behaviour of D16T Drill Pipe in 3.5\% NaCl Solution
}

\author{
Xiaohong Wang ${ }^{*}$, Zhengwei Peng, Shiyu Zhong, Guorong Wang, Qiaogang Hu and Yuanhua Lin** \\ School of Materials Science and Engineering, Southwest Petroleum University, Chengdu 610500, \\ China \\ *E-mail: xhwang3368@ swpu.edu.cn \\ **E-mail: yhlin28@163.com
}

doi: $10.20964 / 2018.09 .65$

Received: 23 May 2018 / Accepted: 7 July 2018 / Published: 5 August 2018

The role of texture in the initiation and expansion of corrosion pits for a D16T aluminium drilling pipe in $3.5 \% \mathrm{NaCl}$ solution was investigated by immersion and electrochemical tests. The results revealed that the surface parallel to the extrusion direction has typical brass $\{110\}<112>$ and copper $\{112\}$ $<111>$ grain orientations, and the surface perpendicular to the extrusion direction has typical $\{112\}$ $<110\rangle,\{111\}<112>$ and $\{001\}<100>$ grain orientations. The $\langle 211>$ orientation sub-grain and subgrain/deformed grain were found to be responsible for the initiation of circular corrosion pits. Furthermore, the surface parallel to the extrusion direction presents a better corrosion resistance and pitting resistance than the surface perpendicular to the extrusion direction in $3.5 \% \mathrm{NaCl}$ solution.

Keywords: aluminium alloy drill pipe, extrusion texture, corrosion behaviour, Pitting density

\section{$\underline{\text { FULL TEXT }}$}

(C) 2018 The Authors. Published by ESG (www.electrochemsci.org). This article is an open access article distributed under the terms and conditions of the Creative Commons Attribution license (http://creativecommons.org/licenses/by/4.0/). 